\title{
VIVEIROS DE CASTRO, E. Metafísicas Canibais - elementos para uma antropologia pós-estrutural. São Paulo: Cosac \& Naify, p. 288, 2015.
}

\author{
Matheus Henrique Pereira da Silva ${ }^{1}$ \\ “... A antropofagia é todo o contrário de uma imagem identitária”. \\ $\left(\right.$ Suely Rolnik) ${ }^{2}$ \\ "Só me interessa o que não é meu. Lei do homem. Lei do antropófago." \\ (Oswald de Andrade) \\ E como diria Viveiros de Castro: "Lei do Antropólogo"
}

O Anti-narciso, um livro que nunca será escrito. Assim, o antropólogo Eduardo Viveiros de Castro homenageia os filósofos Gilles Deleuze e Félix Guattari, através das prodigiosas linhas de Metafísicas Canibais, uma versão possível de Anti-Oedipus legando sua crítica aos grandes divisores ocidentais (Latour, 1991), as unidades ausentes, as concepções "humanistas" ou antropocêntricas de socialidade e, ainda, um esforço para se produzir uma nova imagem do pensamento, antropológico - e que chega ao Brasil após um período de espera, lançado pela editora Cosac \& Naify em 2015.

O livro propõe uma cartografia de regiões por vir na/da antropologia implicadas nos engajamentos e constituições relacionais com outrem, na medida em que há a criação e a invenção (Wagner, 1981) do antropólogo e seu esquema actancial da "cultura" outra, nas conexões parciais junto aos coletivos estudados; portanto as teorias antropológicas podem se construir como versões das teorias nativas, uma vez que se reconhece a sua criatividade enquanto condições de possibilidades da pratica antropológica.

Para Viveiros de Castro, o conhecimento antropológico se dá na constituição de uma relação social, do par etnógrafo-nativo, envolvendo a pressuposição recíproca de que os procedimentos que caracterizam a investigação são conceitualmente da mesma ordem que os procedimentos investigados, ou seja, o antropólogo efetua uma extensão do princípio de simetrização [enquanto efeito de seus engajamentos (Ingold, 2010; Kohn, 2007) com o nativo; entre os agentes humanos, não-humanos e seus fluxos

\footnotetext{
${ }^{1}$ Universidade Federal do Pará, Brasil.

2 Citação extraída do sitio digital Rede Abaeté idealizado e organizado pelos antropólogos Eduardo Viveiros de Castro e Marcio Goldman. Ver: https://sites.google.com/a/abaetenet.net/nansi/abaet\%C3\%A9/cita\%C3\%A7\%C3\%B5es-eep\%C3\%ADgrafes.
} 
semióticos], onde as práticas nativas estabeleceriam uma continuidade epistêmica com as práticas antropológicas de conhecer, apontando, assim, para a problemática das maneiras como uma "cultura" singular pensa, pois tal engajamento implica em como descrever e traduzir, por meio dos conceitos do antropólogo uma cultura outra (Strathern, 2014), cuja forma de descrição é radicalmente diferenciada, uma vez mais que no exercício antropológico opera-se com conceitos, formas e termos analíticos inventados, ou seja, utiliza-se de seus conceitos para falar dos significados de outros.

Portanto, se tratam de uma operação descritiva que consiste em exponenciar as diferenças entre os esquemas actanciais analíticos, tornando-as intensivas e ondulatórias, ou seja, não se trata de "rasurar" as diferenças entre ambas as culturas, ou assimilar a criatividade e descrição do outro, e sim de multiplicar conceitualmente seus pensamentos com outrem; como principio que possibilita que sejam expressos tais mundos possíveis; tais possíveis perspectivas desdobram-se em perspectivas possíveis.

A antropologia, como em Claude Lévi-Strauss, relacionar-se-ia diretamente com o fora: a filosofia, enquanto reguladora dos limites do perímetro do saber cientifico e sua produção de conceitos, metodologias e às variadas abordagens teóricas utilizadas na constituição do pensamento antropológico. Deveríamos, então, subordinar nossas pressuposições culturais à inventividade dos povos estudados, de maneira a afirmar sua criatividade no interior de nossa invenção, igualmente singular. Tais fluxos transformacionais deslocariam o humanismo racionalista das teorias antropológicas totalizadoras, pois a antropologia se constituiria como uma science meneuri, science nômade (Deleuze \& Guattari, 1981).

Então, a antropologia, em sua itinerância, seguir-se-ia as conexões entre singularidades de matéria e seus traços de expressão, coletivos de humanos e nãohumanos, estabelecendo no nível dessas conexões uma contraposição diferencial em relação ao modelo hilemórfico. Tal esquema está baseado numa forma invariável das variáveis, tais como algumas figuras e imagens da alma selvagem narradas pelos jesuítas acercados Tupinambás, no século XVI, enquanto estatua de mármore, não de murta, segundo os pensamentos de uma cultura projetada no outro (Viveiros de Castro, 2002). Pois o que varia não é o conteúdo das relações, mas sua própria figura, que se constitui como tal idéia, pensamento e/ou, relação, entre outras, nesta ou naquela cultura. Deste modo, não são as relações que variam, são as variações que relacionam, ou seja, tal ciência colocaria as variáveis em estado de variação constante. O objeto da 
antropologia seria as variações das relações sociais, admitindo de antemão que se tem uma vaga idéia do que seria esta última, por isso, a colocação da problemática de seguir tais fluxos para se pensar como os índios criam a socialidade, no caso de Viveiros de Castro, englobando sua matriz relacional e possibilitando alternativas às dicotomias infernais, como: uno e múltiplo, individuo e sociedade, cultura e natureza, entre outras.

Pois bem, a imensa contribuição para o pensamento - elaborada conceitualmente, sobretudo com Tânia Stolze Lima (e outros) e junto aos povos amazônicos na América Indígena - nomeada "perspectivismo ameríndio", seria uma cosmologia que imagina-cria-inventa um universo povoado por diferentes tipos de agências e de subjetividades, nas quais humanos e não-humanos são dotados de um tipo genérico de alma, ou seja, um mesmo conjunto de capacidades cognitivas e volitivas em um mundo altamente transformacional. O que as onças vêem como cerveja de mandioca (a bebida adequada de pessoas), os seres humanos vêem como sangue, e assim por diante.

O devir-jaguar do homem, não seu "objeto", revela-se uma imagem genérica do animal, organizada através da correspondência de correlações formais e analógicas com o homem e seus órgãos, tal como no estruturalismo com sua organização simbólica e imaginária “[...], pois devir é um verbo intransitivo (e infinitivo). E tão logo o homem se torna um jaguar, o jaguar não está mais lá” (Viveiros de Castro, 2008), ocorrendo uma transformação real. Então, a humanidade seria a condição comum partilhada pelos agentes, não uma natureza estanque em oposições binárias. Para os ameríndios, a diferença não está na alma, mas sim no corpo, através de suas afecções que efetuam agenciamentos no próprio corpo como superfície topológica - superfície de diferenciação ontológica e disjunção referencial - e onde se operam os devires para produzir as condições de humanidade como tal. "O perspectivismo — a dualidade como multiplicidade - é aquilo que a dialética — a dualidade como unidade — precisa negar para se impor como lei universal" (Viveiros de Castro, 2015).

O perspectivismo ameríndio possui uma teoria de tradução, pois ele efetua uma transcriação (Haroldo de Campos, 2010a, 2010b) das concepções ameríndias em conceitos antropológicos e filosóficos ao realizar um corte no fluxo de enunciados e pensamento indígenas, tal como o xamanismo amazônico que é pensado através desta relação de dupla torção transformativa junto à antropologia do nativo (Wagner, 1981), que também traça suas próprias singularidades cosmológicas em síntese disjuntiva ou 
exclusão imanente. Tal agenciamento possibilita o questionamento de como transformamos/descrevemos tais concepções, na elaboração da linguagem cientifica, as quais têm que se nomear com conceitos para que mais tarde nosso mundo se multiplique e transforme, contendo virtualmente novas formas de criar realidades; produzidas do ponto de vista de uma cultura na relação com outra cultura; nativoetnográfo, etnográfo-nativo; duas multiplicidades comunicantes.

Em outras palavras, o perspectivismo implica um duplo dizer do outro enquanto diferença intensiva: dizer a partir da comunicação entre alteridades e dizê-lo em condição transformada, afinal, o perspectivismo projeta uma imagem de tradução como um processo de equivocação controlada, no sentido de controle da alteridade "referencial" em que se escrevem tais conceitos homonímicos; equívoco, portanto seria um modo de comunicação por excelência entre as diferentes posições de perspectivas.

A partir do pós-estruturalismo das Mitológicas, de Lévi-Strauss, junto a sua experimentação aos Araweté, Viveiros de Castro repensa a metafísica da predação que envolve o canibalismo guerreiro e o xamanismo. A predação ameríndia implica a noção de "parentesco" como uma relacionalidade generalizada, pois a consanguinidade é um valor e próprio limite da afinidade - visto que ele não pode ser atingido - já que se colocam as identidades e antinomias do parentesco em um perpetuo desequilíbrio, como disse Lévi-Strauss. Uma vez que foram apresentadas em seus trabalhos (Viveiros de Castro, 2002), as diferenças entre humanos e deuses são expressas na linguagem da aliança de casamento; a mesma linguagem utilizada para incorporar o inimigo em sua imanência, como modo de subjetivação, quando se relacionam através de sua diferença, e se tornam diferentes através de sua relação enquanto perspectivas transformacionais; uma separação relacionante (n-1). Assim, “A inconstância da alma selvagem”, em sua abertura e plenitude, é a expressão de um modo de ser onde "é a troca, não a identidade, o valor fundamental a ser afirmado" (Clifford, J. In: Viveiros de Castro, 2002).

Já o xamã é simultaneamente o oficiante e o veículo do sacrifício, sendo a própria vítima, ou seja, um morto virtual, já atual e antecipado - como no xamanismo Araweté - que, em suas viagens ao céu, é interpelado pelas divindades canibais desse povo, com a sua alma a ser devorada futuramente. Portanto, o xamã realizaria uma comunicação com as divindades, ainda, ocuparia o ponto de vista do inimigo na dinâmica matador-vitima. Produz-se, ademais, nas palavras do autor, uma "catástrofe fusional" em que há uma identificação instável deste par de agentes. O xamanismo 
amazônico, portanto efetuaria uma comunicação de caráter transversal entre multiplicidades heterogêneas, um confronto de perspectiva onde a humanidade é uma condição genérica para se aceder a um ponto de vista.

Esta antropologia pós-estrutural ultrapassaria a divisão narcísica, nós e eles, para afirmar a síntese disjuntiva entre os termos e possibilitar uma aliança rizomática, onde o antropólogo realizaria sua "arte", nos termos do autor, ao investigar os problemas postos pelas singulares culturas. O livro não apenas apresenta uma sofisticação das praticas-teóricas do autor, mas a radicalização de uma antropolo(fa)gia, retomando o pensamento enquanto potência de alteridade, visto que a disciplina é constantemente guiada para criar as condições ontológicas voltada a autodeterminação dos povos que estuda. A antropologia comprometer-se-ia com princípios ético-políticos mais que epistemológicos, de tornar possível um estranhamento e a descolonização permanente do pensamento; então assim comemoramos uma renovação da antropologia brasileira.

\section{Referências}

CAMPOS, H. Metalinguagem e outras metas: ensaios de teoria e crítica literária. São Paulo: Perspectiva, 2010 a.

CAMPOS, H. A arte no horizonte do provável. São Paulo: Perspectiva, 2010 b.

DELEUZE, G. \& GUATTARI, F. Milles plateaux. Capitalisme et schizophrénie. Paris: Minuit, 1981.

INGOLD, T. 'Bindings against boundaries: entanglements of life in an open world'. Environment and Planning A, v. 40, n. 8, p. 1796-1810, 2008.

KOHN, E. How Dogs Dream: Amazonian Natures and the Politics of Transspecies Engagement. American Ethnologist, v. 34, n. 1, p. 3-24, 2007.

LATOUR, B. Nous n'avons jamais etémodernes. Paris: Ed. La Découverte, 1991.

STRATHERN, M.O efeito etnográfico e outros ensaios. São Paulo: Cosac \& Naify, 2014.

VIVEIROS DE CASTRO, E. A Inconstância da alma selvagem - e outros ensaios de antropologia. São Paulo: Cosac \& Naify, 2002.

Metafísicas Canibais - elementos para uma antropologia pós-estrutural. São Paulo: Cosac \& Naify, 2015.

Xamanismo transversal: Lévi-Strauss e a cosmopolítica amazônica. In: QUEIROZ,

R. de C.; NOBRE, R. F. (Org.). Lévi-Strauss: leituras brasileiras. Belo Horizonte: Editora UFMG, p. 79-124, 2008.

WAGNER, R. The Invention of Culture. Chicago: University Press., 1981.

Recebido em: 27/10/2016.

Aprovado em: 07/12/2016. 